\title{
Production of glyceryl monostearate by immobilized candida antarctica B lipase in organic media
}

\begin{abstract}
Chemical methods of synthesizing monoglycerides (MGs) produce mixture of acylglycerols making the synthesis of MGs of a single fatty acid type not possible through this route. Lipases due to their selectivity and specificity offer a useful way of synthesizing highly purified single fatty acid containing monoglycerides. Glyceryl monostearate (GMS), a nonionic amphiphilic monoglyceride of glycerol and stearic acid is widely used as emulsifier in food, cosmetic, pharmaceutical and textile industry. In the present work, lipase mediated synthesis of GMS was explored using Novozym 435 and indigenously immobilized Candida antarctica B lipase. Direct esterification of glycerol and stearic acid was used as strategy and various parameters that influence synthesis of glyceryl monostearate such as molar ratio of substrates, enzyme load, reaction time and solvent polarity were systematically studied using Novozym 435 lipase. Esterification efficiency of indigenously immobilized Candida antarctica B lipase and Novozym 435 was compared for synthesis of GMS and indigenously immobilized Candida antarctica $\mathrm{B}$ lipase gave conversion competitive to Novozym 435. Indigenously immobilized Candida antarctica B lipase in the presence of homogenous substrate solution using tert-butyl alcohol as the reaction medium, resulted in exclusive production of monoglyceride without formation of diglyceride. Continuous production of GMS was also carried out in packed bed reactor and $94 \%$ conversion of stearic acid was achieved.
\end{abstract}

Keywords: lipase, tert-butyl alcohol, candida Antarctica, novozym 435, stearic acid, esterification, monoglycerides
Volume 2 Issue 3 - 2017

Kavadia MR, Yadav MG, Odaneth AA, Arvind M Lali

DBT-ICT-Centre for Energy Biosciences, India

Correspondence: Annmmma A Odaneth, Assistant Professor in Biochemistry, DBT-ICT Centre for Energy Biosciences, Institute of Chemical Technology, Nathalal Parikh Marg, Mumbai-400 019, Mahrashtra, India, Fax +9|-22-24I456|4, Tel +91-22-33612312, Email a.dbtceb@gmail.com

Received: October 27, 2016 | Published: February 28, 2017
Abbreviations: MGs, monoglycerides; GMS, glyceryl monostearate; RP-HPLC, reversed phase high performance liquid chromatography; HPLC, high-performance liquid chromatography

\section{Introduction}

Monoglycerides are esters of fatty acids and glycerol which contain an aliphatic lipophilic chain contributed by fatty acyl group and two hydroxyl groups form the hydrophilic part contributed by glycerol. Because of this amphiphilic nature monoglycerides are capable of stabilizing emulsions which make them most important emulsifiers in food and cosmetic industry. ${ }^{1}$ Due to their emulsifying property, monoglycerides find diverse applications as components of nano and liposomal formulations for drug delivery systems in pharmaceutical industry. ${ }^{2,3}$ Glyceryl monostearate is an industrially useful monoacylglycerol of stearic acid a long chain saturated fatty acid and it is commercially manufactured by continuous glycerolysis of triglycerides at high temperatures $\left(220^{\circ} \mathrm{C}-250^{\circ} \mathrm{C}\right)$ using inorganic chemical catalysts such as sulfuric acid/sulfonic acid/ NaOH/KOH/ $\mathrm{Ca}(\mathrm{OH})_{2}$ under nitrogen gas atmosphere. This method of synthesis occurs in a random manner and leads to a mixture of mono, di and triglycerides in general (40:50:10) and short path distillation is employed to obtain high purity mono acylglycerol. ${ }^{4-6}$ Another major drawback of this mode of synthesis is use of high temperature that leads to dark-colored product and burnt taste that can cause undesirable effects in the final products in which they are incorporated. Chemical glycerolysis gives low yields (40-60\%) and involve high energy consumption due to use of elevated temperatures. Considering these key sustainability challenges it has become increasingly necessary to look for environmentally benign processes such as enzyme based synthesis because enzymes are considered green catalysts. Enzymatic synthesis is carried out using gentle operating conditions such as lower temperature, ambient pressure that make this synthesis process safe and non-hazardous to the environment. Enzymes due to their natural design possess additional advantage of regioselectivity and specificity not achievable with chemical catalysis thereby producing highly pure end products greatly minimizing cost intensive and environment degrading purification steps. Using enzymes it is possible to obtain end product with high content of monoacylglycerol without short path distillation step that is an essential step in chemical synthesis. ${ }^{7}$ Mild reaction conditions afforded by enzymatic processes also help reduce the overall energy consumption greatly improving industry economics. ${ }^{8,9}$ Wide amount of literature is available on enzymatic production of monoacylglycerols of different fatty acids using various types of lipases under different reaction conditions by mainly two routes namely esterification between glycerol and fatty acid and glycerolysis of vegetable oil. ${ }^{4,10-12}$ Glycerolysis of oils is not favored when the target product is monoglyceride because it leads to a mixture of mono, di and triglycerides and repeated molecular distillation steps are needed to obtain pure product. Also monoglycerides produced by this method are not of a single type because oils contain different types of fatty acids and selective formation of a particular monoglyceride is not possible through glycerolysis. Esterification of glycerol and fatty acid is preferred method when monoglyceride of a particular fatty acid is needed because pure fatty acids can be selected at the start of the reaction. Thus by choosing appropriate starting materials coupled with enzyme specificity and efficient reaction engineering esterification can lead to selective production of monoglycerides. ${ }^{13,25}$ For esterification reactions, miscibility of glycerol and fatty acids is 
major factor controlling higher conversions. As the two substrates have opposite polarities and monophasic reaction medium is needed to effect efficient esterification. Generally, single or binary solvent systems or pre-treated glycerol have been reported for homogenous reaction media. ${ }^{13,14,23}$ This work reports an enzymatic process for the synthesis of GMS using Novozym 435. Effect of different reaction parameters such as substrate molar ratio, solvent effect, reaction time and enzyme load was studied. Continuous enzymatic process for synthesis of GMS was also studied. The main objective of the work was to obtain selective synthesis of monoglycerides using underivatized starting materials in a single solvent. The esterification reaction for synthesis of GMS has been shown in Figure 1.

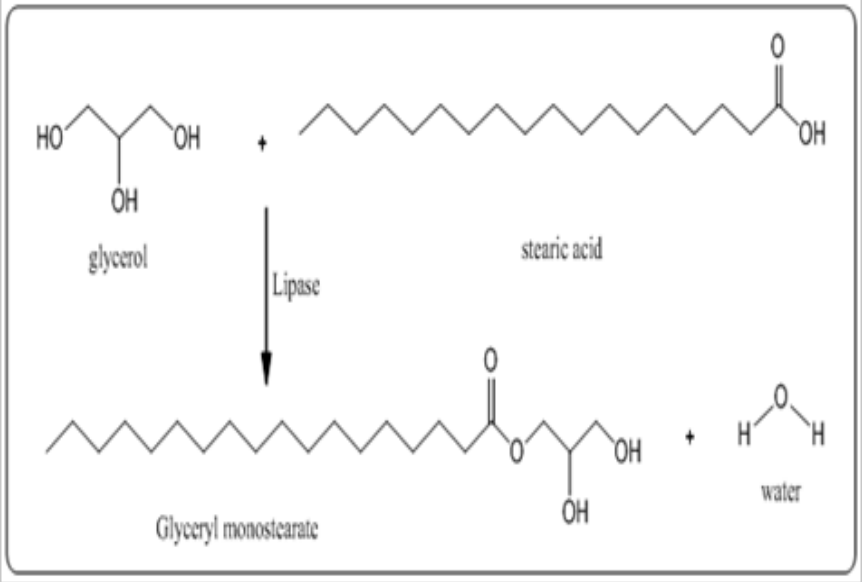

Figure I Reaction scheme showing esterification of stearic acid and glycerol by lipase.

\section{Materials and methods}

\section{Chemicals and lipases}

All chemicals and solvents used were of analytical or chromatographic grade and purchased from SD Fine Chemicals (Mumbai, India). Novozym 435 was obtained as gift from Novo Nordisk Ltd. (Bagsvaerd, Denmark). Candida antarctica B soluble lipase was purchased from DK Enzymes \& Chemicals (India). Indion PA 500 resin was purchased from Ion Exchange, (India). Molecular sieves of $3 \AA$ were purchased from Hi-Media Laboratories (India). Reference standards of $s n$-1(3) glyceryl monostearate, glyceryl 1,3-distearate and stearic acid $(>99.0 \%)$ were purchased from Sigma-Aldrich (USA). Stearic acid and glycerol used as substrates for esterification reaction were gifted by Godrej Industries (India). All chemicals and solvents were used without any modification/ purification.

\section{Experimental methodology}

Esterification reaction in batch scale: Synthesis of glyceryl monostearate was performed as batch process in $100 \mathrm{ml}$ conical flask with stoppered cap, thermo stated to the desired operating temperature and reaction blend was mixed using orbital shaker. Reaction mixture contained appropriate amount of stearic acid, glycerol and organic solvent. Novozym 435 was added to the reaction mixture to start the esterification reaction. Samples were withdrawn from reaction mixture at pre specified time intervals and analyzed using method developed on reversed phase high performance liquid chromatography (RP-HPLC) equipped with a UV detector as explained in Section 5.2.2. Percentage conversion was determined on the basis of reduction of stearic acid in the final reaction mixture as shown in Equation 1 using standard calibration curve of stearic acid. Monoacylglycerol content was determined using response factor obtained from calibration curve of standard glyceryl monostearate. Effect of molecular sieves on esterification rate was also studied, wherein; particular amount of molecular sieves $\left(3 \mathrm{~A}^{\circ}\right)$ was added for removal of water generated during esterification reaction. In the present work, effect of molar ratio of stearic acid and glycerol, enzyme load, type of organic solvent and reaction time on the esterification efficiency of stearic acid and glycerol has been systematically studied. Structure of formed ester was confirmed using FT-IR, mass spectrometry and $\mathrm{H}^{1}$-NMR.

\section{Equation I}

$\%$ conversion of stearic acid (HPLC) $=$ amount of stearic acid in final reaction mixture $\times 100$ amount of stearic acid at $0 \mathrm{~h}$.

Analysis of reaction mixture: For analysis of reaction mixture specific amount of sample was withdrawn. Reaction products were analyzed by reversed phase high-performance liquid chromatography (HPLC) in an Agilent 1200 Chromatography System (CA, USA) equipped with a quaternary solvent delivery module and an Agilent UV detector at wavelength of $208 \mathrm{~nm}$. Reaction mixture was appropriately diluted using HPLC grade tertiary butyl alcohol and $10 \mu 1$ sample was automatically injected on Agilent Zorbax XDB ODS $5 \mu \mathrm{M}, 4.6 \times 150 \mathrm{~mm}$ column. Separation was obtained by isocratic elution using methanol/water $(90: 10)$ as solvent system. The flow rate was maintained at $1 \mathrm{ml} / \mathrm{min}$ and total run time was kept at $30 \mathrm{~min}$. Calibration curves were plotted for reference standard of stearic acid and $s n-1(3)$ glyceryl monostearate using the above method and linear equations were calculated for determination of percent conversion of stearic acid and monoacylglycerol content in final reaction mixture respectively. The degree of conversion was expressed as \% reduction of stearic acid in the final reaction mixture as determined by HPLC analysis.

\section{Results and discussion}

\section{Effect of molar ratio of substrates}

Lipases, sn-1, 3 specific and non-specific have been reported in literature for the esterification reaction giving varied degree of conversion and diverse products. ${ }^{26}$ In the present study Novozym 435 lipase which is non-specific was evaluated for synthesis of glyceryl monostearate. Effect of different molar ratios of stearic acid and glycerol was studied to understand its influence on conversion of fatty acid into monoester. Molar ratio of substrates plays an important role in determining the overall fate of enzyme catalyzed esterification reaction because an optimum interaction of enzyme molecules with substrate is needed to bring about maximum conversion. Reactions were set up using molar ratio of 1:1, 1:3, 1:5, 1:8 and 1:10 using stearic acid as limiting substrate. As illustrated in Table 1 conversion increased with increasing concentration of glycerol and conversion reached $\sim 89 \%$ for 1:8 molar ratio with no significant change when molar ratio was increased to 1:10 (Figure 2). Only a minor increase in conversion $\sim 9 \%$ was seen when molar ratio was increased from 1:5 to 1:10 compared to the drastic increase in conversion of $\sim 36 \%$ when molar ratio was increased from 1:1 to 1:5. In the present study we also investigated influence of molecular sieves on esterification of stearic acid and glycerol. For obtaining high conversion it is necessary to remove water which is a direct product of esterification reaction to prevent reverse hydrolysis reaction that can lead to reduced conversions. 
Water plays an important role in determining reaction equilibrium and distribution of products in the reaction medium because lipases can catalyze both esterification and hydrolysis reaction depending on the water content of reaction medium., ${ }^{4,12,19,20}$ Water removal has been tried by several authors by carrying out reactions in the presence of molecular sieves or under reduced pressure. ${ }^{4}$ In the present work as shown in Figure 2 addition of molecular sieves $(150 \mathrm{~g} / \mathrm{L})$ was found to positively push the conversion for all the molar ratios studied with maximum conversion reaching $\sim 95 \%$ for $1: 8$ molar ratio.

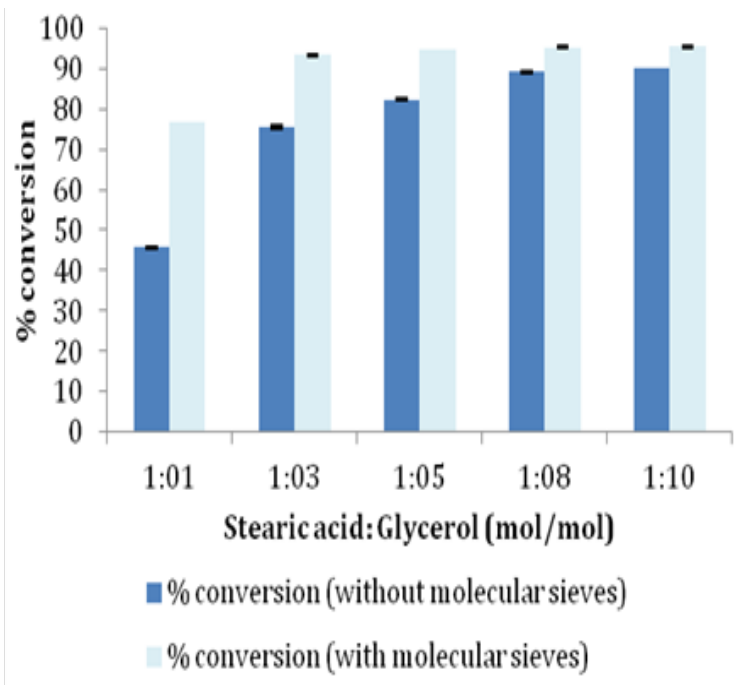

Figure 2 Effect of molar ratio of stearic acid and glycerol. Reaction was carried for $24 \mathrm{~h}$ at $60^{\circ} \mathrm{C}$. Reaction mixture consisted of $10 \% \mathrm{w} / \mathrm{v}$ substrate concentration and $20 \% \mathrm{w} / \mathrm{w}$ Novozym 435 , operating temperature was $60^{\circ} \mathrm{C}$. Vertical bars represent standard deviation.

Table I Conversion profiles for different molar ratios with and without of molecular sieves

\begin{tabular}{lll}
\hline $\begin{array}{l}\text { Molar ratios } \\
\text { (Stearic Acid/ } \\
\text { Glycerol) }\end{array}$ & $\begin{array}{l}\text { \% Conversion } \\
\text { (Without molecular } \\
\text { sieves) }\end{array}$ & $\begin{array}{l}\text { \% Conversion (with } \\
\text { molecular sieves) }\end{array}$ \\
\hline 이:01 & 45.68 & 80.43 \\
이:03 & 75.44 & 93.35 \\
이:05 & 82.3 & 94.78 \\
$01: 08$ & 89.22 & 95.32 \\
$01: 10$ & 90.23 & 95.42 \\
\hline
\end{tabular}

For any enzymatic process to be commercially feasible it is desired to have an enzyme with high conversion capability in short reaction time to reduce overall process costs. ${ }^{21}$ In the present work esterification reaction was monitored over a period of 24 hours using 1:3 molar ratio of stearic acid/glycerol at $60^{\circ} \mathrm{C}$. Figure 3 shows the effect of reaction time on the esterification efficiency and formation of glyceryl monostearate. Reduction of stearic acid by $\sim 82 \%$ was obtained in $2 \mathrm{~h}$ using Novozym 435. In this esterification system it was observed that $s n-1 / 3$ glyceryl monostearate was the major monoacylglycerol with trace amounts of $s n-2$ glyceryl monostearate as shown in Figure 4 indicating that Novozym 435 showed 1, 3-regiospecificity in the prepared reaction system and glycerol was mainly esterified with fatty acyl groups at $s n-1 / s n-3$ position with very less esterification at the secondary hydroxyl group of glycerol. Esterification using Novozym 435 did not lead to DAG formation which was confirmed by injecting standard reference standard of glyceryl 1,3-distearate on HPLC. Based on these results $2 \mathrm{~h}$ reaction time was found to be the most optimum time for esterification using Novozym 435 as catalyst. Monteiro et al. ${ }^{23}$ reported conversion of $65 \%$ of lauric acid into monolaurin using a mixture of $n$-hexane/tert-butanol in 8 hour reaction time. Gofferjé et al. ${ }^{19}$ reported $86 \%$ conversion of free fatty acids of Jatropha oil and glycerol in 10 hours using Rhizomucor miehei lipase under solvent free conditions. In the present study rapid esterification occurred which could be attributed to high selectivity and activity of Novozym 435 in the esterification reaction system that mainly favored synthesis of $s n-1(3)$ isomer of glyceryl monostearate.

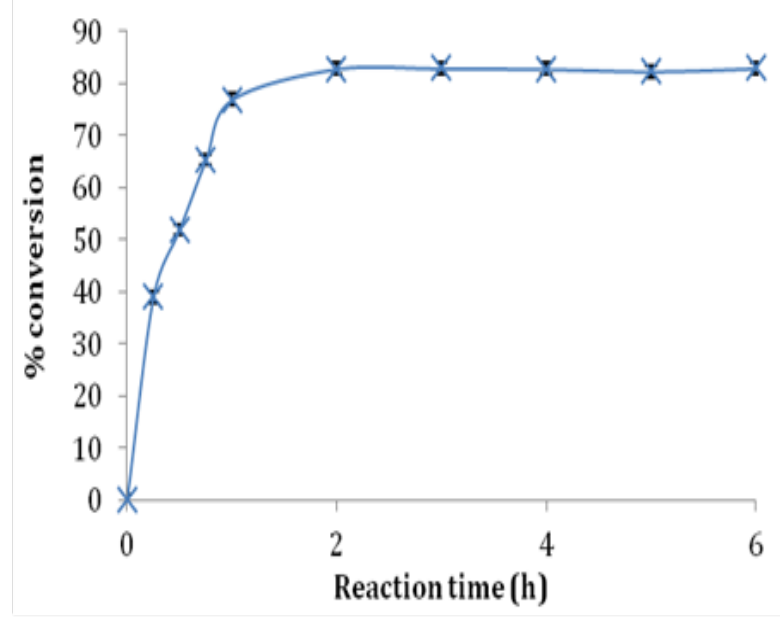

Figure 3 Effect of reaction time on esterification of glycerol and stearic acid. Reaction mixture consisted of 1:3 molar ratio of stearic acid/glycerol at 10\% substrate concentration, $20 \% \mathrm{w} / \mathrm{w}$ Novozym 435, operating temperature was $60^{\circ} \mathrm{C}$. Vertical bars represent standard deviation.

\section{Effect of organic solvent}

Glycerol and stearic acid have opposite polarities and are not miscible with each other. For the formation of monophasic reaction mixture it is necessary to introduce organic solvents to solubilize both stearic acid and glycerol. Use of organic solvents enables good mixing of substrates and plays a critical role in improving mass transfer in the reaction medium by reducing viscosity of the reaction medium. Organic solvents also affect the reaction kinetics by causing conformational changes in enzyme molecules thereby influencing activity and selectivity of enzyme. The effects differ depending on the kind of organic solvents and enzymes used. Conformational changes in enzymes have been reported to result in alteration of substrate specificity and affinity of substrates for enzymes. ${ }^{18,21,23}$ In this work, several organic solvents with different $\log \mathrm{P}$ values were screened for their effect on synthesis of glyceryl monostearate. Table 2 and Figure 5 illustrate the details of $\log \mathrm{P}$ values and effect of different organic solvents such as tetrahydrofuran, tertiary butyl alcohol, acetone, hexane, heptane and isooctane on stearic acid conversion. In our current work we observed that tertiary butyl alcohol was the most efficient solvent for esterification of stearic acid and glycerol showing conversion of $82.71 \%$. The second best esterification was observed in the case of acetone with conversion being $\sim 69 \%$. Less esterification efficiency was observed in the case of hexane, heptane and isooctane which could be due to hydrophobicity (high $\log P$ value) of these solvents preventing proper contact of hydrophilic glycerol with lipophilic stearic acid in the reaction medium leading to reduced conversions. Janssen et al. ${ }^{17}$ has extensively studied effect of organic 
solvents with varying $\log \mathrm{P}$ values and have suggested that tertiary alcohols are better suited for monoester synthesis by esterification route.

Table 2 Effect of organic solvents having varying log P values on conversion of stearic acid

\begin{tabular}{lll}
\hline Organic solvent & Log P & \% conversion of stearic acid \\
\hline Acetone & -0.24 & 69.34 \\
Tetrahydrofuran & 0.46 & 28.28 \\
Tert-butyl alcohol & 0.35 & 82.71 \\
Iso-octane & 4.5 & 33.84 \\
Hexane & 3.9 & 39.8 \\
Heptane & 4.66 & 40.78 \\
\hline
\end{tabular}

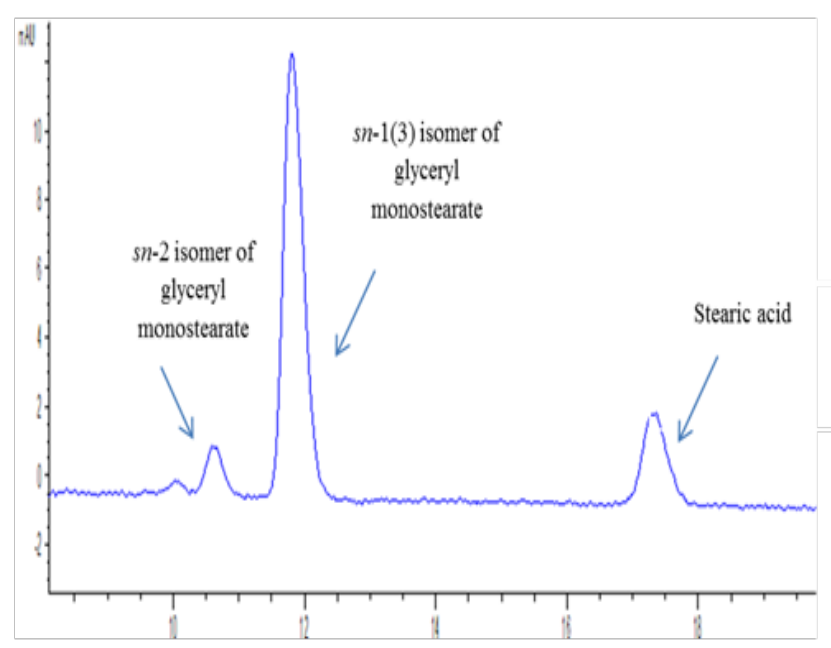

Figure 4 HPLC chromatogram showing sn- 2 isomer of glyceryl monostearate, sn-I(3) isomer of glyceryl monostearate and stearic acid. Separation was performed as described in Section 5.2.3.

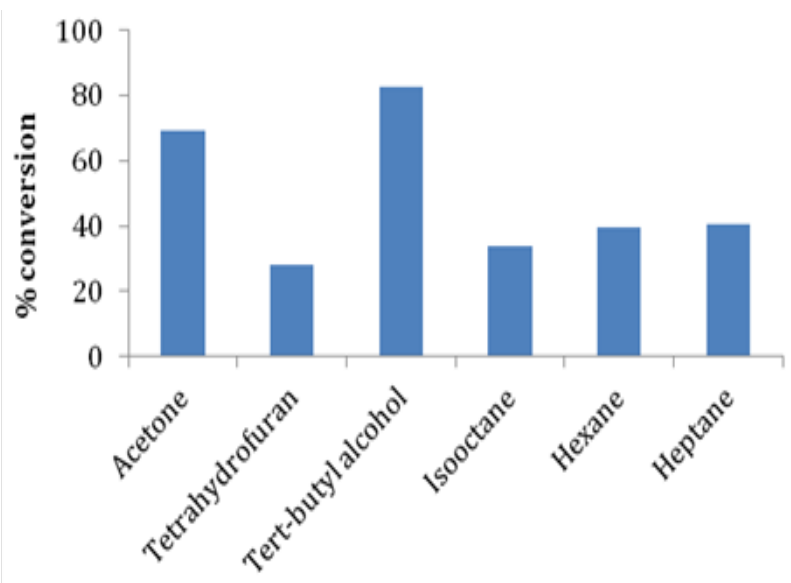

Figure 5 Effect of organic solvents with different log $\mathrm{P}$ values on conversion. Reaction mixture consisted of $\mathrm{I}: 3$ molar ratio of stearic acid/glycerol at I0\%w/v substrate concentration, $20 \% \mathrm{w} / \mathrm{w}$ Novozym 435 , operating temperature was $60^{\circ} \mathrm{C}$. Vertical bars represent standard deviation.

\section{Effect of enzyme load}

It is desirable to obtain high conversions using low enzyme load as cost of enzymes is the primary factor to be accounted to make enzyme mediated processes economically viable in industry. ${ }^{22}$ In order to understand effect of lipase load on esterification of glycerol and stearic acid enzyme load was varied from $1 \%$ to $40 \% \mathrm{w} / \mathrm{w}$ of limiting substrate stearic acid. Effect of enzyme load on conversion of stearic acid is shown in Figure 5. Increasing the amount of Novozym 435 lipase from $1 \%$ to $5 \%$ sharply increased the conversion of stearic acid as calculated by Equation 1 between $5 \%$ to $10 \%$ of enzyme load there was only a slight increase of $\sim 4 \%$ in conversion and beyond $10 \%$ there was no significant change in overall conversion. Enzyme load beyond $10 \%$ did not increase conversion which is desirable as lower enzyme load is necessary to reduce overall production costs Ziobrowski et al. ${ }^{16}$ obtained $90 \%$ conversion of stearic acid using Novozym 435 at $35 \% \mathrm{w} / \mathrm{w}$ for $1: 7$ molar ratio of stearic acid and glycerol in $6 \mathrm{~h}$ whereas we report significantly less enzyme loading for the same extent of conversion using Novozym 435 lipase (Figure 6).

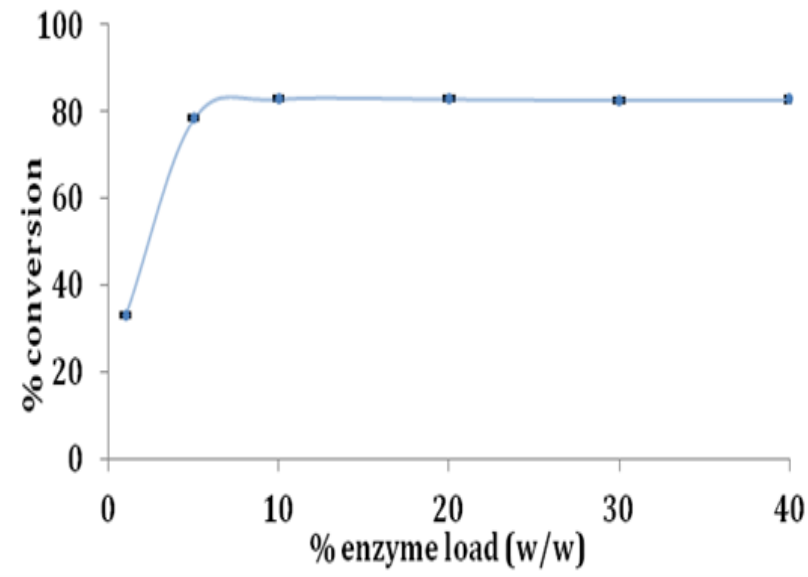

Figure 6 Effect of enzyme load on conversion. Reaction mixture consisted of $\mathrm{I}: 3 \mathrm{molar}$ ratio of stearic acid/glycerol at $10 \% \mathrm{w} / \mathrm{v}$ substrate concentration; operating temperature was $60^{\circ} \mathrm{C}$.Vertical bars represent standard deviation.

\section{Packed bed reactor studies}

Packed bed reactor (PBR) provides better reaction efficiency due to improved heat transfer mass transfer and reactant reserve time. A packed bed reactor allows for continuous production of desired product using a very simple reactor design. PBR offers advantage of reduced reaction time and high conversion per unit mass of catalyst. ${ }^{24}$ Due to these advantages, esterification between stearic acid and glycerol was performed in a packed bed reactor using 1:3 molar ratio (stearic acid/glycerol) in both presence and absence of molecular sieves. Effect of residence time which is major factor that controls conversion in a packed bed reactor was studied. Enzyme and molecular sieves were packed in two separate water jacketed glass cylinder reactors which were connected in series. The ratio of height to diameter of glass reactor was kept 4:1.15g Novozym 435 lipase was uniformly packed and column was equilibrated with tertiary butyl alcohol before passing substrate feed. Stearic acid glycerol and tertiary butyl alcohol were mixed to obtain 1:3 molar ratio (stearic acid/glycerol) $10 \%$ substrate concentration and temperature of both reactors was maintained at $60^{\circ} \mathrm{C}$.

Effect of residence time: As shown in Figure $7 \%$ conversion of stearic acid was $77 \%$ and $82 \%$ for residence time of 5 min and 10 min respectively. Conversion did not show any significant change even when greater contact time was provided between enzyme and 
substrates. This could be due to water formed in the esterification reaction that resulted in no further esterification after 10 minutes of residence time. The highest conversion of stearic acid obtained was $82.39 \%$ at 10 min. Enzyme purification is avoided using PBR and selectivity was maintained such that only GMS was produced and no diester formation was observed.

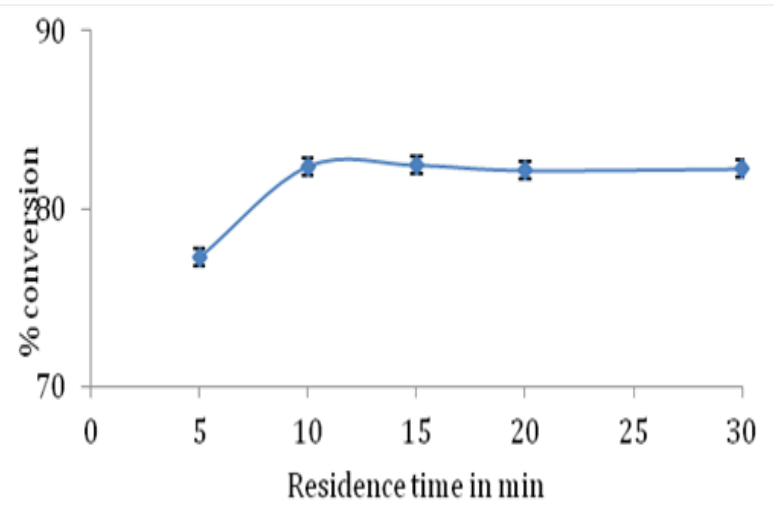

Figure 7 Effect of residence time on conversion. Reaction mixture consisted of 1:3 molar ratio of stearic acid/glycerol at 10\% substrate concentration, I5g Novozym 435 , operating temperature was $60^{\circ} \mathrm{C}$. Vertical bars represent standard deviation.

Effect of molecular sieves: Substrate mixture was passed through enzyme packed bed reactor for optimized residence time of $10 \mathrm{~min}$. Two separate studies were conducted in the first study (Figure 8A) substrate feed was passed only through enzyme packed bed reactor and in the second study (Figure 8B) substrate feed was passed through enzyme reactor $(10 \mathrm{~min})$ followed by packed bed reactor containing molecular sieves for $10 \mathrm{~min}$ and again passed through enzyme packed bed reactor for $10 \mathrm{~min}$. It was observed that conversion of stearic acid increased from $82.39 \%$ to $94.14 \%$ when molecular sieves were used.

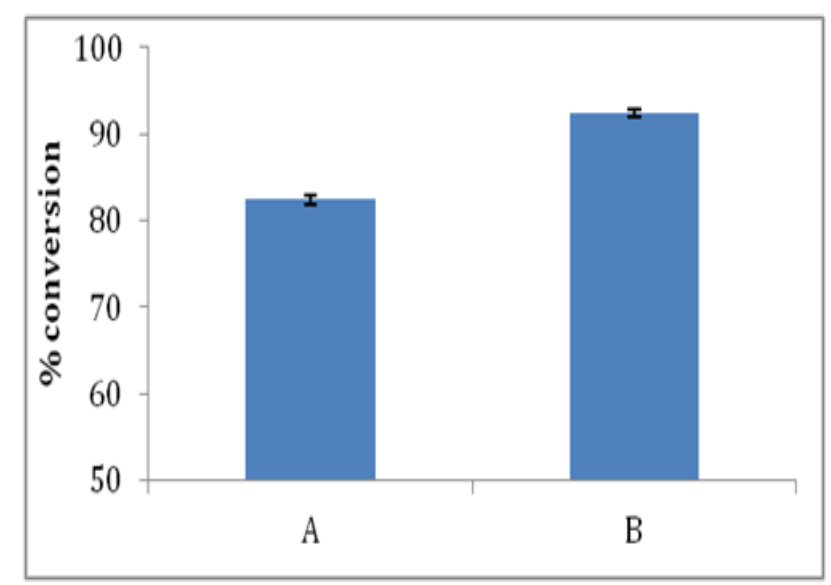

Figure 8 Comparative esterification study in packed bed reactor.

A. Without molecular sieves and

B. With molecular sieves. Reaction mixture consisted of 1:3 molar ratio of stearic acid/glycerol at $10 \%$ substrate concentration; operating temperature was $60^{\circ} \mathrm{C}$.Vertical bars represent standard deviation.

\section{Comparative study of indigenously immobilized Can- dida Antarctica B lipase and novozym 435}

Candida antarctica B lipase was immobilized in our laboratory on polystyrene divinyl-benzene beads of Indion PA 500 resin by physical adsorption (which was named as PyCal) and used as biocatalyst for production of glyceryl monostearate [27 unpublished results]. Using optimized reaction parameters such as 1:3 molar ratio of stearic acid and glycerol, $10 \% \mathrm{w} / \mathrm{w}$ enzyme load, $10 \%$ w/v substrate concentration, esterification reaction was set up with Candida antarctica B lipase. Table 3 and Figure 9 show adsorbent characteristics of the two enzymes and conversion. It was observed that indigenously immobilized Candida antarctica B lipase PyCal resulted in comparable conversion with commercial lipase Novozym 435. PyCal lipase also promoted selective synthesis of GMS with no DAG formation. This study indicates the feasibility of using cheaper alternatives to Novozym 435 for monoglyceride synthesis with same efficiency.

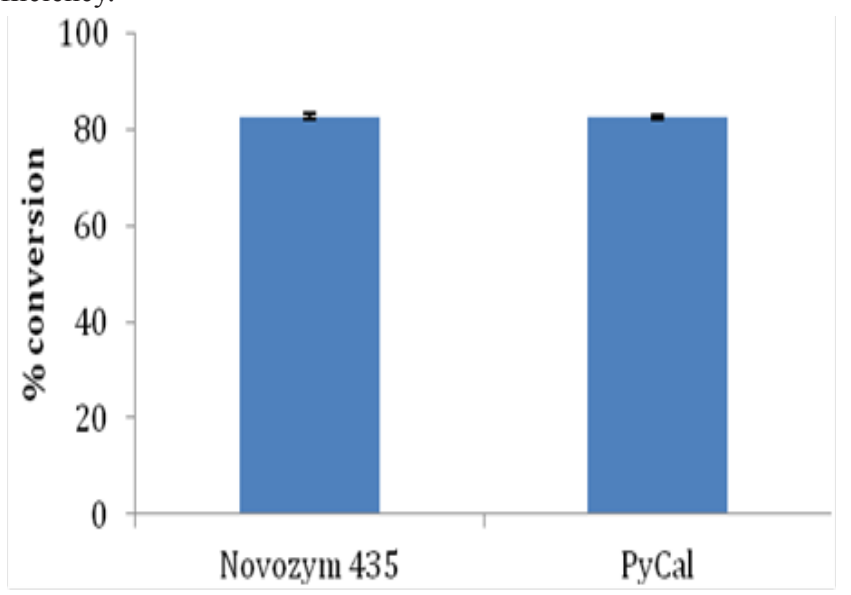

Figure 9 Comparative esterification study between Novozym 435 and PyCal. Reaction mixture consisted of $1: 3$ molar ratio of stearic acid/glycerol at 10\% substrate concentration, $10 \% \mathrm{w} / \mathrm{w}$ enzyme load operating temperature was $60^{\circ} \mathrm{C}$. Vertical bars represent standard deviation.

\section{Structural validation of synthesized GMS}

FT-IR analysis: The ester functional group in formed glyceryl monostearate was confirmed using Fourier Transform Infrared Spectrophotometer (Shimadzu, Japan) equipped with DlaTGS detector. The recorded spectrum resulted from co-addition of 40 scans at resolution of $4 \mathrm{~cm}^{-1}$. A comparison of FT-IR spectrum of initial and final sample is presented in Figure 10. As seen in FT- IR spectrum, band in region $1698 \mathrm{~cm}^{-1}$ is due to $\mathrm{C}=\mathrm{O}$ stretching vibration typical of fatty acid present in the starting material band in the region of $1728 \mathrm{~cm}^{-1}$ is due to $\mathrm{C}=\mathrm{O}$ stretching vibration of synthesized GMS and band in region $3200-3300 \mathrm{~cm}^{-1}$ is due to $\mathrm{OH}$ stretching vibration of free hydroxyl groups of synthesized GMS.

MS analysis: A mass spectrum of the final reaction product was recorded on a Triple quadruple mass spectrometer (Agilent 1200 series) equipped with an electro spray ion source. Total ion signal from the sample was obtained by scanning the range of mass corresponding to $\mathrm{m} / \mathrm{z}$ values ranging from 100 to 500 in positive ion mode. The mass spectrum of the final product showed molecular ion peak (M) having mass-to-charge ratio of 358.60 which confirms the product as glyceryl monostearate. The mass spectrum of formed GMS is shown in Figure 11.

$\mathbf{H}^{1}$-NMR analysis: $\mathrm{H}^{1}$-NMR spectrum of the product as shown in Figure $12\left(500 \mathrm{MHz}, \mathrm{CDCl}_{3}: \delta(\mathrm{ppm}): 4.20 ; 4.15\left(\mathrm{~m}, 2 \mathrm{H},-\mathrm{CH}_{2}-\mathrm{O}-\mathrm{CO}\right)\right.$, $3.92(\mathrm{~m}, 1 \mathrm{H},-\mathrm{CH}), 3.7 ; 3.6\left(\mathrm{~m}, 2 \mathrm{H},-\mathrm{CH}_{2}\right), 2.66(\mathrm{~s}, 1 \mathrm{H},-\mathrm{OH}), 2.35(\mathrm{t}$, $\left.2 \mathrm{H},-\mathrm{CH}_{2}-\mathrm{CO}-\mathrm{O}\right), 2.24(\mathrm{~s}, 1 \mathrm{H},-\mathrm{OH}), 1.60\left(\mathrm{~m}, 2 \mathrm{H},-\mathrm{CH}_{2}\right), 1.30(\mathrm{~m}, 2 \mathrm{H}$, $\left.4-\mathrm{CH}_{2}\right), 1.25\left(\mathrm{~m}, 2 \mathrm{H}, 10-\mathrm{CH}_{2}\right), 0.88\left(\mathrm{t}, 3 \mathrm{H},-\mathrm{CH}_{3}\right)$. 
Table 3 Comparative details of Novozym 435 and indigenously immobilized lipase PyCal

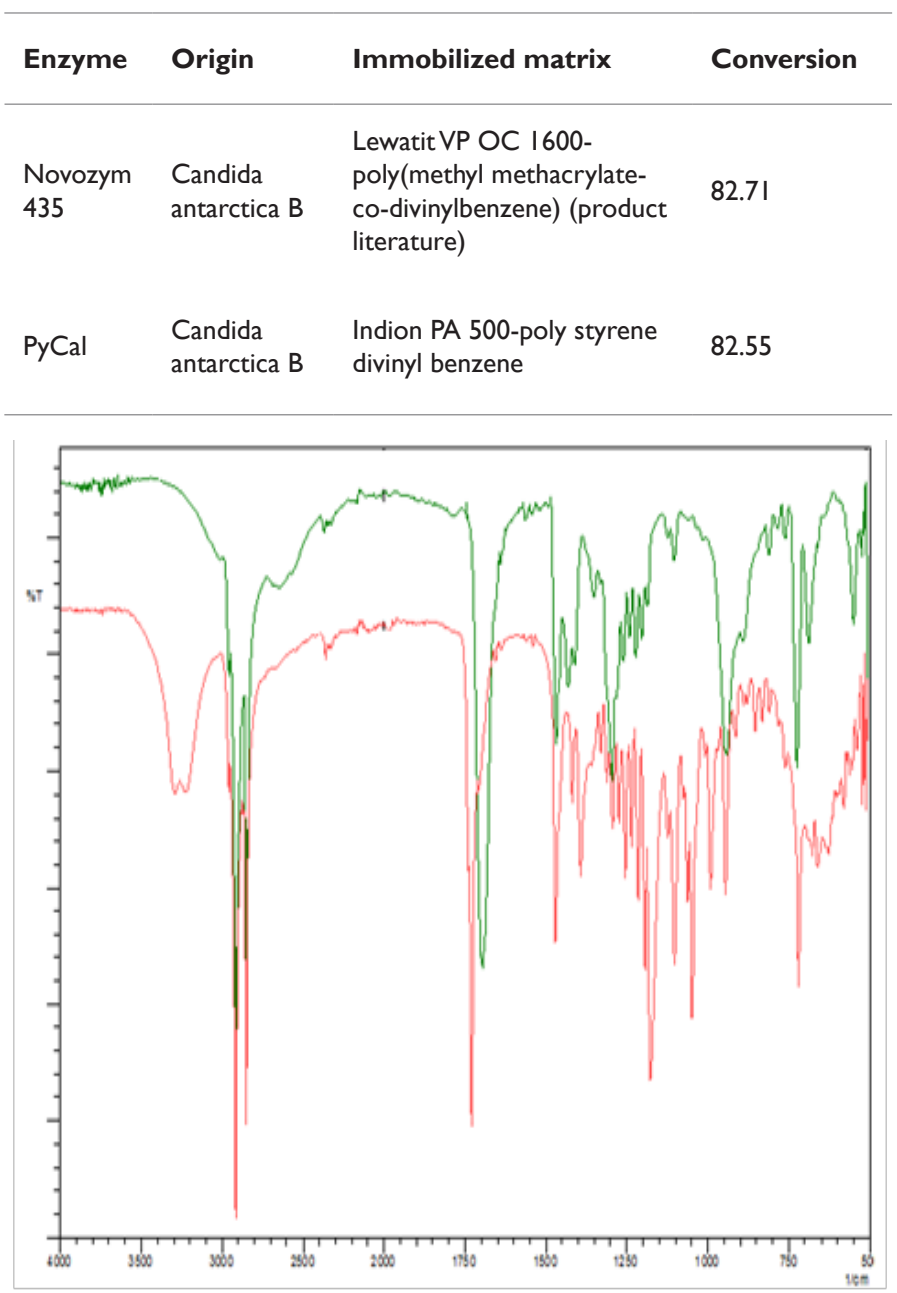

Figure 10 Stacked ATR-FTIR spectra of stearic acid and synthesized GMS.

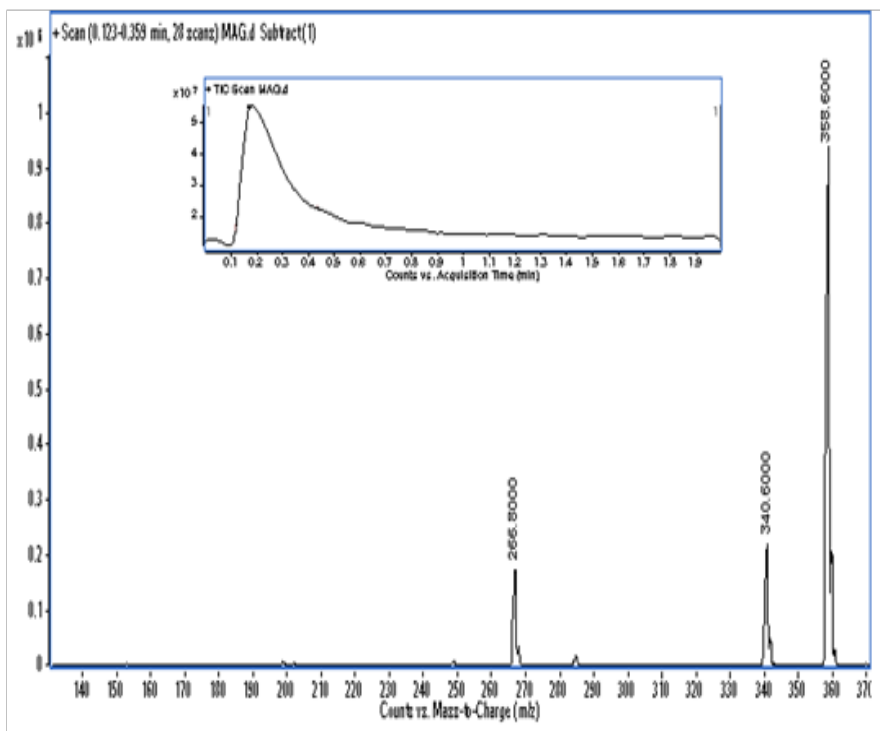

Figure II Mass spectrum of synthesized glyceryl monostearate. (Inset showing Total ion chromatogram of the formed ester).

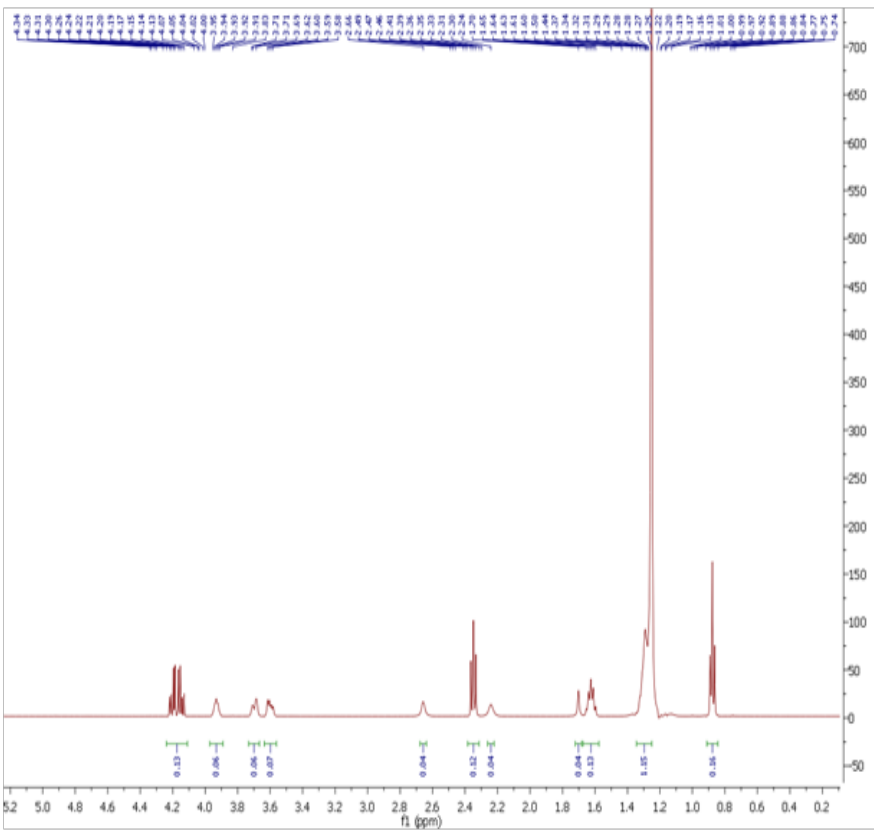

Figure $12 \mathrm{H}^{\prime}-\mathrm{NMR}\left(500 \mathrm{MHz}, \mathrm{CDCl}_{3}\right)$ of synthesized glyceryl monostearate.

\section{Conclusion}

The present work reports synthesis of GMS using Novozym 435 and indigenously immobilized Candida antarctica B lipase. Indigenously immobilized Candida antarctica B lipase PyCal gave competitive results to that of Novozym 435. Considering high cost of commercial lipases use of indigenously immobilized lipases is advantageous for large scale production of monoglycerides. The reported esterification process is a convenient and green route for production of high purity monoglycerides which can be used as a reference for industrial enzymatic synthesis of monoglycerides.

\section{Acknowledgements}

The authors are grateful to the financial support provided by Department of Biotechnology under the Ministry of Science and Technology, Govt of India. The authors have declared no conflicts of interest.

\section{Conflict of interest}

The author declares no conflict of interest.

\section{References}

1. Pakamas C, Chakrit T. Synthesis of high purity monoglycerides from crude glycerol and palm stearin. J Sci Technol. 2008;30(4):515-521.

2. Pouton CW. Lipid formulations for oral administration of drugs: non-emulsifying self-emulsifying and self-microemulsifying drug delivery systems. Eur J Pharm Sci. 2000;11(Suppl 2):93-98.

3. Mengesha AE, Wydra RJ, Hilt JZ, et al. Binary blend of glyceryl monooleate and glyceryl monostearate for magnetically induced thermo-responsive local drug delivery system. Pharm Res. 2013;30(12):3214 3224.

4. Bornscheuer UT. Lipase-catalyzed syntheses of monoacylglycerols. Enzyme and Microbial technology. 1995;17(7):578-586. 
5. Temelli F, King JW, List GR. Conversion of oils to monoglycerides by glycerolysis in supercritical carbon dioxide media. JAOCS. 1996;73(6):699-706.

6. Yu CC, Lee YS, Cheon BS, et al. Synthesis of glycerol monostearate with high purity. Bull Korean Chem Soc. 2003;24(8):1229.

7. Gunstone FD. Enzymes as biocatalysts in the modification of natural lipids. J Sci Food Agric. 1999;79(12):1535-1549.

8. Byun HG, Eom TK, Jung WK, et al. Lipase catalyzed production of monoacylglycerols by the esterification of fish oil fatty acids with glycerol. Biotechnology and Bioprocess Engineering. 2007;12:491.

9. Speranza P, Macedo GA. Lipase-mediated production of specific lipids with improved biological and physicochemical properties. Process Biochemistry. 2012;47(12):1699-1706.

10. Akoh CC, Cooper C, Nwosu CV. Lipase G-catalyzed synthesis of monoglycerides in organic solvent and analysis by HPLC. JAOCS. 1992;69(3):257-260.

11. Garcia HS, Yang B, Parkin KL. Continuous reactor for enzymic glycerolysis of butteroil in the absence of solvent. Food Research International. 1995;28(6):605-609.

12. Xuebing Xu. Engineering of enzymatic reactions and reactors for lipid modification and synthesis. Eur J Lipid Sci Technol. 2003;105(6):289304.

13. Bellot JC, Choisnard L, Castillo E, et al. Combining solvent engineering and thermodynamic modeling to enhance selectivity during monoglyceride synthesis by lipase-catalyzed esterification. Enzyme Microb Technol. 2001;28(4-5):362-369.

14. Berger M, Schneider M P. Enzymatic esterification of glycerol II. Lipase-catalyzed synthesis of regioisomerically pure 1(3)-rac-monoacylglycerols. JAOCS. 1992;69(10):961-965.

15. Freitas L, Perez VH, Santos JC, et al. Enzymatic synthesis of glyceride esters in solvent-free system: influence of the molar ratio lipase source and functional activating agent of the support. J Braz Chem Soc. 2007;18(7):1360-1366.
16. Ziobrowski Z, Kiss K, Rotkegel A, et al. Pervaporation aided enzymatic production of glycerol monostearate in organic solvents. Desalination. 2009;241(1-3):212-217.

17. Janssen AE, Padt VA, Riet KV. Solvent effects on lipase-catalyzed esterification of glycerol and fatty acids. Biotechnol Bioeng. 1993;42(8):953962.

18. Yesiloglu Y, Kilic I. Lipase-catalyzed esterification of glycerol and oleic acid. JAOCS. 2004;81(3):281-284.

19. Gofferjé G, Stäbler A, Herfellner T, et al. Kinetics of enzymatic esterification of glycerol and free fatty acids incrude Jatropha oil by immobilized lipase from Rhizomucor miehei. Jornal of Molecular Catalysis B: Enzymatic. 2014;107:1-7.

20. Yahya ARM, Anderson WA, Moo-Young M. Ester synthesis in lipase catalyzed reactions. Enzyme and Microbial Technology. 1998;23(78):438-450

21. Zhao H, Lu Z, Lu F, et al. Lipase-catalyzed acidolysis of lard with caprylic acid to produce structured lipid. IFST. 2006;41(9):1027-1032.

22. Zhong H, Fang Z, Zou B, et al. Studies on the lipase-catalyzed esterification of alkyl oleates in solvent-free systems. Journal of Molecular Catalysis B: Enzymatic. 2013;90:114-117.

23. Monteiro JB, Nascimento MG, Ninow JL. Lipase-catalyzed synthesis of monoacylglycerol in a homogeneous system. Biotechnol Lett. 2003;25(8):641-644.

24. Phuah ET, Tang TK, Lee YY, et al. Review on the current state of diacylglycerol production using enzymatic approach. Food Bioprocess Technol. 2015;8(6):1169-1186

25. Langone MA, Abreu DME, Rezende MJ, et al. Enzymatic synthesis of medium chain monoglycerides in a solvent-free system. Appl Biochem Biotechnol. 2002;98(100):987-996.

26. Karmee SK. Lipase catalyzed synthesis of ester-based surfactants from biomass derivatives. Biofuels Bioprod Bioref. 2008;(2):144-154.

27. Manish G Yadav. Strategies for enzyme mediated synthesis of fatty acid esters; 2017. 